\title{
Whole-body cryotherapy: empirical evidence and theoretical perspectives
}

This article was published in the following Dove Press journal:

Open Access Journal of Sports Medicine

10 March 2014

Number of times this article has been viewed

\section{Chris M Bleakley' \\ François Bieuzen ${ }^{2}$ \\ Gareth W Davison' \\ Joseph T Costello 3}

'Sport and Exercise Science Research Institute, Faculty of Life and Health

Sciences, University of Ulster,

Newtownabbey, Northern Ireland;

${ }^{2}$ Research Department, Laboratory of Sport, Expertise and Performance, French National Institute of Sport (INSEP), Paris, France; ${ }^{3} \mathrm{School}$ of Exercise and Nutrition Sciences and Institute of Health and Biomedical Innovation, Queensland University of Technology, Brisbane, Australia
Correspondence: Chris Bleakley Ulster Sports Academy, University of Ulster, Newtownabbey, County Antrim, BT370QB, Northern Ireland Tel +44289036 66025

Email c.bleakley@ulster.ac.uk
Abstract: Whole-body cryotherapy (WBC) involves short exposures to air temperatures below $-100^{\circ} \mathrm{C}$. WBC is increasingly accessible to athletes, and is purported to enhance recovery after exercise and facilitate rehabilitation postinjury. Our objective was to review the efficacy and effectiveness of WBC using empirical evidence from controlled trials. We found ten relevant reports; the majority were based on small numbers of active athletes aged less than 35 years. Although WBC produces a large temperature gradient for tissue cooling, the relatively poor thermal conductivity of air prevents significant subcutaneous and core body cooling. There is weak evidence from controlled studies that WBC enhances antioxidant capacity and parasympathetic reactivation, and alters inflammatory pathways relevant to sports recovery. A series of small randomized studies found WBC offers improvements in subjective recovery and muscle soreness following metabolic or mechanical overload, but little benefit towards functional recovery. There is evidence from one study only that WBC may assist rehabilitation for adhesive capsulitis of the shoulder. There were no adverse events associated with WBC; however, studies did not seem to undertake active surveillance of predefined adverse events. Until further research is available, athletes should remain cognizant that less expensive modes of cryotherapy, such as local ice-pack application or cold-water immersion, offer comparable physiological and clinical effects to WBC.

Keywords: whole-body cryotherapy, cooling, recovery, muscle damage, sport

\section{Introduction}

Cryotherapy is defined as body cooling for therapeutic purposes. In sports and exercise medicine, cryotherapy has traditionally been applied using ice packs or cold-water immersion (CWI) baths. Recently, whole-body cryotherapy (WBC) has become a popular mode of cryotherapy. This involves exposure to extremely cold dry air (usually between $-100^{\circ} \mathrm{C}$ and $-140^{\circ} \mathrm{C}$ ) in an environmentally controlled room for short periods of time (typically between 2 and 5 minutes). During these exposures, individuals wear minimal clothing, gloves, a woolen headband covering the ears, a nose and mouth mask, and dry shoes and socks to reduce the risk of cold-related injury. Although it was originally developed to treat chronic medical conditions, such as multiple sclerosis and rheumatoid arthritis, ${ }^{1} \mathrm{WBC}$ is being increasingly employed by athletes. Its purported effects include decreased tissue temperature, reduction in inflammation, analgesia, and enhanced recovery following exercise. WBC is typically initiated within the early stages (within 0-24 hours) after exercise and may be repeated several times in the same day or multiple times over a number of weeks. 
WBC is becoming increasingly accessible for athletes. It is considerably more expensive than traditional forms of cryotherapy, but it is not clear whether it offers any additional clinical effect. A recent review by Banfi et $\mathrm{al}^{2}$ found observational evidence that WBC modifies many important biochemical and physiological parameters in human athletes. These include a decrease in proinflammatory cytokines, adaptive changes in antioxidant status, and positive effects on muscular enzymes associated with muscle damage (creatine kinase and lactate dehydrogenase). They also concluded that exposure to WBC is safe and does not deleteriously effect cardiac or immunological function. However, when this review $^{2}$ was published, few randomized trials examining the efficacy of the treatment had been completed. Further, the conclusions were predominantly based on lower-quality observational studies, which did not include a control group and therefore should be treated with caution.

A common supposition is that the extreme nature of WBC offers significant advantages over traditional methods of cooling, such as CWI or ice-pack application. Recently, there has been a large increase in the volume of research investigating the effects of WBC. Our aim is to update the evidence base, with a particular focus on reviewing empirical evidence derived from controlled studies. The objectives were: 1) to quantify the tissue-temperature reductions associated with WBC and compare these with traditional forms of cryotherapy; 2) to examine the biochemical and physiological effects of WBC exposure compared to a control, and to determine any associated adverse effects; and 3) to consider the strength of the clinical evidence base supporting its use in sports recovery and soft-tissue injury management.

\section{Materials and methods}

A literature search was undertaken using Medline, Embase, and the Cochrane Controlled Trials Register up to October 2013. For our first objective, we sourced any studies quantifying temperature reductions associated with WBC. We extracted data (mean \pm standard deviation) on skin, intramuscular, and core-temperature reductions induced by WBC. No restrictions were made on the temperature-measurement device. For comparison, we used a convenience sample of studies reporting tissue-temperature reductions induced by ice-pack application (crushed ice) and CWI based on durations of 10 minutes and 5 minutes, respectively. These durations were selected as they align well with current clinical practice. ${ }^{3,4}$

For our second objective, we focused on studies fulfilling the following inclusion criteria: controlled studies comparing WBC intervention to a control group (observational studies and studies using within-subject designs were excluded); the temperature of exposure had to have been at least $-100^{\circ} \mathrm{C}$, though there were no restrictions placed on the number of exposures; participants could be healthy, or recovering from exercise or soft-tissue injury at the time of the intervention; no restrictions were made on participants' age, sex, or training status. We extracted all data relating to biochemical, physiological, or performance/clinical outcomes.

Key study characteristics were extracted by the primary researcher and tabulated. Outcomes were subgrouped into biochemical, perceived sensation, and performance-based measures. We were particularly interested in between-group differences based on follow-up scores. Where possible, effect sizes (standardized mean differences [MDs] and 95\% confidence intervals [CIs]) were calculated from group means and standard deviations, using RevMan software (version 5.2; Nordic Cochrane Centre, Copenhagen, Denmark).

\section{Characteristics of controlled studies}

Key study characteristics ${ }^{5-14}$ are summarized in Table 1. Three studies ${ }^{8,10,13}$ used randomized controlled designs, with all incorporating high-quality methods based on computergenerated randomization, allocation concealment, and blinded outcome assessment. The remainder of the studies ${ }^{5-7,9,11,12,14}$ used controlled or crossover designs, with washout periods varying between $3^{7}$ and 16 weeks. $^{5}$

The majority of studies were undertaken using young, active participants with mean ages under 35 years. Just under $40 \%$ of participants were females. Four studies recruited high-performance athletes. ${ }^{5-8}$ In three studies, ${ }^{9,10,12}$ the objective was simply to examine the effect of WBC compared to an untreated control intervention using a sample of healthy participants. Six studies ${ }^{5-8,10,11}$ used WBC either in the early stages after exercise or intermittently throughout a particular training block. One study ${ }^{13}$ investigated the clinical effectiveness of WBC using a sample of participants with adhesive capsulitis of the shoulder joint.

In all studies, the WBC intervention involved a brief exposure to an acclimatization chamber or prechamber before entering a therapy chamber at $-110^{\circ} \mathrm{C}$ to $-195^{\circ} \mathrm{C}$ for 2.5-3 minutes. The total number of treatment sessions varied between one session on a single day ${ }^{12}$ up to $20-24$ sessions over a period of weeks. ${ }^{5,13}$

\section{Results}

\section{Tissue-temperature reductions}

Table 2 shows the relative temperature reductions associated with typical applications of ice packs, CWI, and WBC. ${ }^{12,15-29}$ 


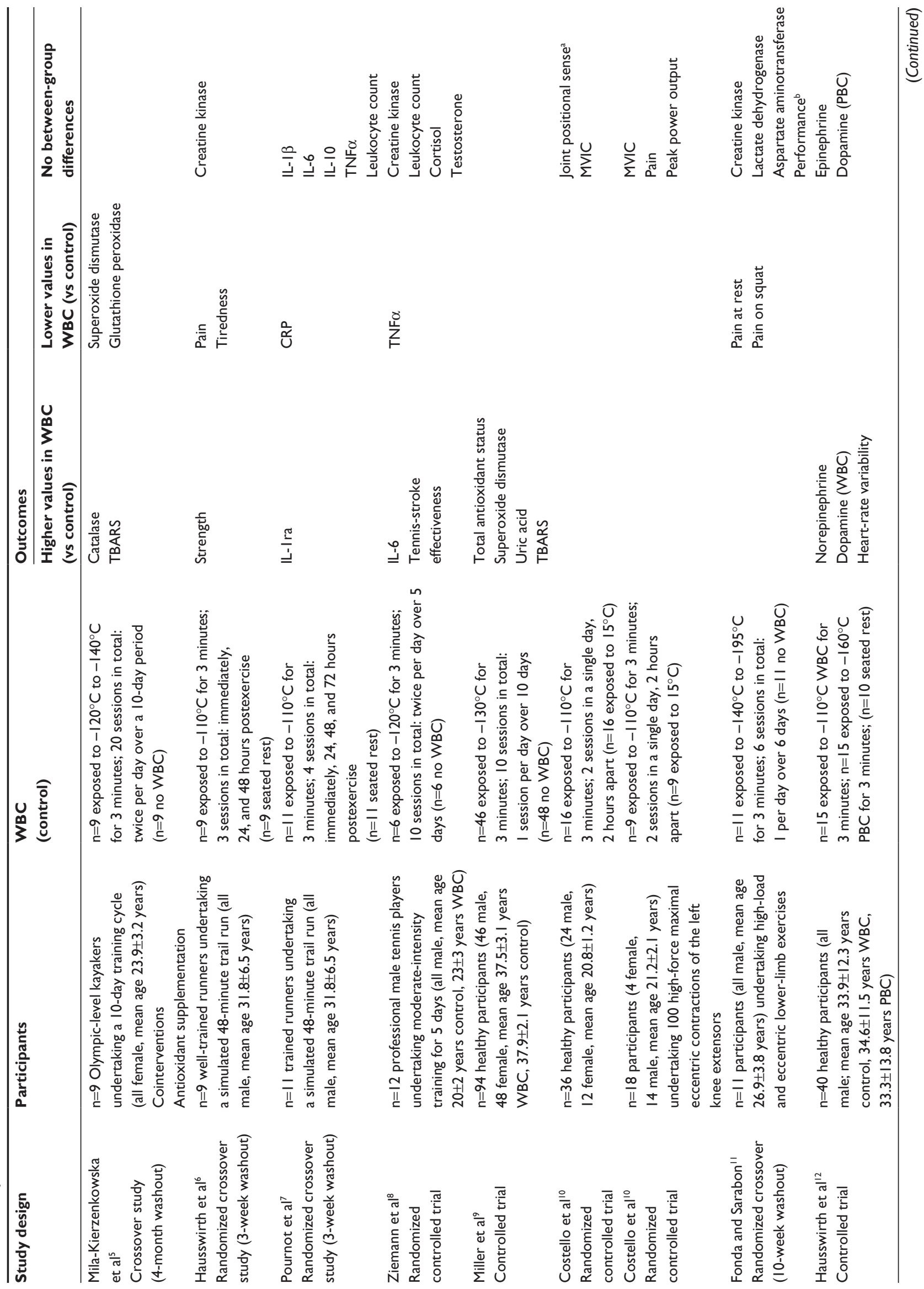




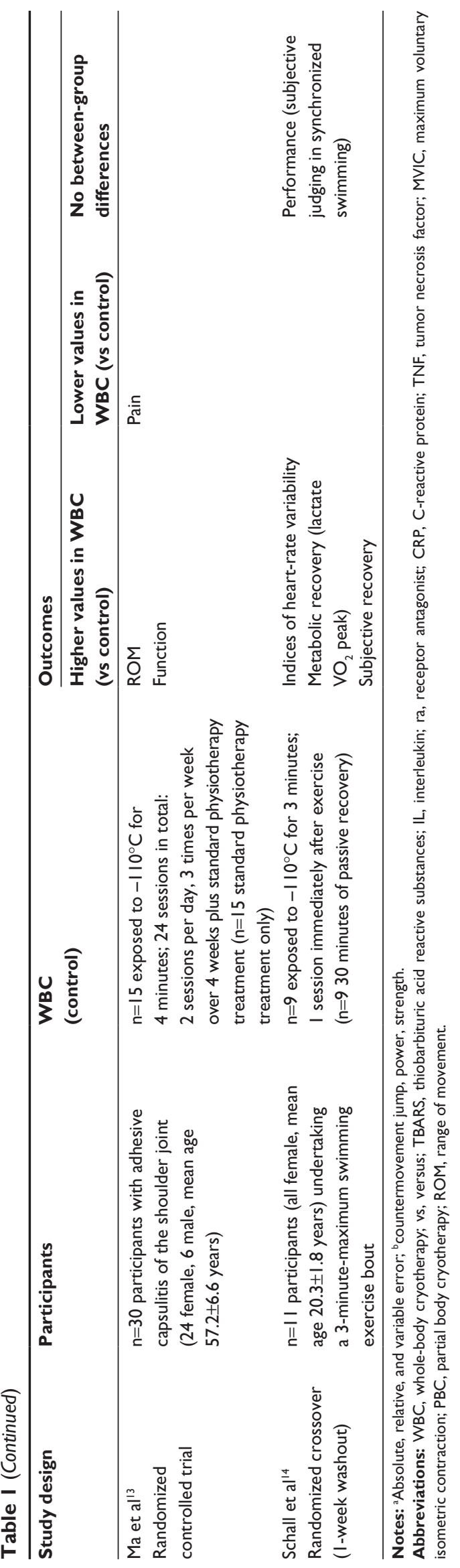

Table 2 Tissue-temperature reductions by cooling modalities

\begin{tabular}{|c|c|c|c|}
\hline & $\begin{array}{l}\text { Ice pack } \\
\text { (10 minutes) }\end{array}$ & $\begin{array}{l}\text { CWI } \\
(4-5 \text { minutes, } \\
\left.8^{\circ} \mathrm{C}-10^{\circ} \mathrm{C}\right)\end{array}$ & $\begin{array}{l}\text { WBC } \\
\text { (3 minutes) }\end{array}$ \\
\hline Skin & $18^{b, 15}$ & $6.2(0.5)^{24}$ & $3.5-8.7^{27}$ \\
\hline \multirow[t]{6}{*}{ temperature } & $20^{a, 16}$ & $8.4(0.7)^{25}$ & $6.7^{\mathrm{b}, 28}$ \\
\hline & $20^{b, 17}$ & $9.0(0.8)^{26}$ & $8.1(0.4)^{c, 12}$ \\
\hline & $20^{18}$ & & $12.1(1.0)^{25}$ \\
\hline & $22^{\mathrm{a}, \mathrm{b}, 19}$ & & $10.3(0.6)^{26}$ \\
\hline & $25.7-26.4^{20}$ & & $13.7(0.7)^{12}$ \\
\hline & & & $19.4^{b, 29}$ \\
\hline Intramuscular & $1.76(1.37)^{21}$ & $1.7(0.9)^{25}$ & I. $2(0.7)^{25}$ \\
\hline temperature & $2.0^{\mathrm{a}, 16}$ & & \\
\hline \multirow[t]{3}{*}{ (2 cm depth) } & $2.0^{a, b, 19}$ & & \\
\hline & $2.7^{\mathrm{b}, 15}$ & & \\
\hline & $-3.88(1.83)^{22}$ & & \\
\hline Core & $0^{a, 16}$ & $0.2(0.1)^{24}$ & $0^{29}$ \\
\hline temperature & $0^{23}$ & $0.4(0.2)^{25}$ & $0.3(0.2)^{25}$ \\
\hline
\end{tabular}

Notes: ${ }^{a}$ Data extracted from graphs with permission: Arch Phys Med Rehabil, 200 I;82, Jutte LS, Merrick MA, Ingersoll CD, Edwards JE. The relationship between intramuscular temperature, skin temperature, and adipose thickness during cryotherapy and rewarming. 845-850.16 @ 2001 with permission from Elsevier; and Merrick MA, Jutte LS, Smith ME. Cold modalities with different thermodynamic properties produce different surface and intramuscular temperatures. J Athl Train. 2003;38:28-33. ${ }^{19}$ bstandard deviation not available. PBC. All values are degrees celsius (means \pm standard deviation).

Abbreviations: CWI, cold-water immersion; WBC, whole-body cryotherapy; PBC, partial body cryotherapy (head out).

The largest skin-temperature reductions seemed to be associated with ice-pack application. The skin-temperature reductions associated with CWI and WBC seemed to vary slightly across studies. Two studies ${ }^{25,26}$ reported similar skin temperatures associated with a 4-minute WBC exposure at $-110^{\circ} \mathrm{C}$ (thigh, $17.9^{\circ} \mathrm{C} \pm 1.4^{\circ} \mathrm{C}$; knee, $19.0^{\circ} \mathrm{C} \pm 0.9^{\circ} \mathrm{C}$ ) and a 4-minute CWI at $8^{\circ} \mathrm{C}$ (thigh, $21.3^{\circ} \mathrm{C} \pm 1.2^{\circ} \mathrm{C}$; knee, $20.5^{\circ} \mathrm{C} \pm 0.6^{\circ} \mathrm{C}$ ). Table 2 clearly highlights that subcutaneous tissue temperature reductions were consistently small regardless of the cooling medium. Intramuscular temperatures at $2 \mathrm{~cm}$ depth were rarely cooled below $2^{\circ} \mathrm{C}$. Again, there were trends that ice packs induced slightly larger intramuscular temperature reductions in comparison to CWI and WBC. Core-temperature reductions were consistently small across all cooling modes.

\section{Inflammatory biomarkers}

Pournot et $\mathrm{al}^{7}$ compared a WBC intervention to a passive control after an intense simulated trail run using high-level athletes. Levels of inflammatory biomarkers (interleukin [IL]-1 $\beta$, IL-1 receptor antagonist [ra], IL-6, IL-10, tumor necrosis factor $[\mathrm{TNF}]-\alpha$, and leukocytes) during the 4-day recovery period were generally similar in each group. The largest between-group differences were higher IL-1 ra immediately after the first exposure, and lower concentration of C-reactive protein at 24, 48, 72, and 96 hours postexercise within the WBC condition. In a small study, Ziemann et $\mathrm{al}^{8}$ 
randomized professional tennis players to undertake twicedaily WBC or no intervention during a 5-day training camp. Two of the participants in this study could not be randomized due to contraindications to WBC and were therefore preselected for the control intervention. Their results showed an enhanced cytokine profile within the WBC group, with lower levels of TNF $\alpha$ and a higher concentration of IL-6.

\section{Muscle damage}

There was evidence from three studies ${ }^{6,8,11}$ that WBC does not affect markers of muscle damage after exercise. These studies found few differences between WBC and control groups in creatine kinase, lactate dehydrogenase, and aspartate aminotransferase during recovery from exercise-induced muscle damage (EIMD), ${ }^{11}$ intense running, ${ }^{6}$ or 5 days of moderate-intensity tennis training. ${ }^{8}$

\section{Oxidative stress}

Miller et $\mathrm{al}^{9}$ examined oxidative stress and antioxidant function using a group of nonexercising participants. The results showed an increase in antioxidant status associated with WBC in comparison to the untreated control group; however, there were only small between-group differences in relation to lipid peroxidation. As oxidative stress and antioxidant function were quantified at two different sites (ie, vascular and intracellular), it is difficult to conclude a strong relationship between WBC and free radical production. In a crossover study, Mila-Kierzenkowska et $\mathrm{al}^{5}$ examined antioxidant status in Olympic kayakers undertaking training cycles both with and without WBC stimulation (twice per day). Results showed an attenuation of oxidative stress as measured by lipid peroxidation in the WBC group over the course of a 10-day training bout. This finding did not align with the majority of the athletes' enzymatic profiles (superoxide dismutase and glutathione peroxidase), which were also surprisingly lower in the WBC condition in comparison to the exercise-only condition.

\section{Autonomic nervous system}

Hausswirth et $\mathrm{al}^{12}$ reported significant increases in norepinephrine concentrations in the immediate stages after cryostimulation compared to resting controls. They found similar between-group differences in resting vagal-related heart-rate variability indices (the root-mean-square difference of successive normal R-R intervals, and high-frequency band). An interesting caveat was that the magnitude of these effects was reduced when participants substituted WBC for a partial body cryostimulation that did not involve head cooling. Another randomized study ${ }^{12}$ examined the effects that WBC has on autonomic function, with a primary focus on parasympathetic reactivation after two maximal synchronized swimming bouts. Comparisons were made against active, passive, and contrast water-therapy conditions. The WBC condition $\left(3\right.$ minutes at $-110^{\circ} \mathrm{C}$ ) had the largest influence on parasympathetic reactivation, with large increases across a range of similar heart-rate variability indices.

\section{Perceived and functional recovery}

Using a randomized controlled design, Costello et al ${ }^{10}$ found that 3-minute exposures at $-110^{\circ} \mathrm{C}$ had little effect on joint positional sense and muscle function compared to control exposures at $15^{\circ} \mathrm{C}$. A follow-up study within the same report ${ }^{10}$ examined the effectiveness of WBC compared to resting control using a subgroup of participants exposed to EIMD: results showed few differences between groups in terms of participants' strength, power, and muscle soreness. Fonda and Sarabon ${ }^{11}$ also investigated the effects of $\mathrm{WBC}$ on functional recovery after EIMD, but incorporated a more intense cooling dose based on temperatures of $-195^{\circ} \mathrm{C}$, using a liquid nitrogen system, and treatment up to 6 days postexercise. These investigators also found few significant differences between groups in relation to strength and power output; however, they reported significantly lower muscle soreness in favor of WBC. It is important to consider that Costello et $\mathrm{al}^{10}$ incorporated a randomized controlled design, allocation concealment, and blinded outcome assessor, and was less open to selection and reporting bias.

Two studies investigated the effects of WBC on functional recovery after running- or sporting-based activities. Hausswirth et $\mathrm{al}^{6}$ found that undertaking WBC immediately and at 24 and 48 hours after intense trail running resulted in significant improvements in strength, pain, and subjective fatigue compared to untreated controls. Ziemann et $\mathrm{al}^{8}$ also recorded improved functional recovery associated with WBC within a group of elite tennis players. They found that athletes incorporating twice-daily exposure to $-120^{\circ} \mathrm{C}$ during a 5-day training camp had greater shot accuracy during two testing sessions, compared to an untreated control. These findings may be subject to detection bias, as blinded outcome assessors were not employed.

Schaal et $\mathrm{al}^{14}$ found that compared to a passive control, a single WBC exposure $\left(3\right.$ minutes at $\left.-110^{\circ} \mathrm{C}\right)$ enhanced subjective and metabolic recovery (based on blood lactate and $\mathrm{VO}_{2 \max }$ ) after intense bouts of swimming. This study found few differences when comparisons were made to an active recovery condition. Figures 1 and 2 provide a summary of the effects of WBC on perceived and functional recovery after exercise when compared to control intervention. 
Study or subgroup

1.3.1 pain at rest 24 hours

Costello ${ }^{10}$

Fonda $^{11}$

Hausswirth $^{6}$

1.3.2 pain at rest 48 hours

Costello ${ }^{10}$

Fonda ${ }^{11}$

Hausswirth $^{6}$

1.3.3 pain at rest 72 hours

Costello ${ }^{10}$

Fonda ${ }^{11}$

1.3.4 pain at rest 96 hours

Costello ${ }^{10}$

Fonda ${ }^{11}$

1.3.5 pain on movement 24 hours

Fonda $^{11}$

1.3.6 pain on movement 48 hours

Fonda $^{11}$

1.3.7 pain on movement 72 hours

Fonda $^{11}$

1.3.8 pain on movement 96 hours Fonda $^{11}$

1.3.9 tiredness at 24 hours

Hausswirth $^{6}$

1.3.10 tiredness at 48 hours

Hausswirth $^{6}$
Standardized mean difference

IV, fixed, $95 \% \mathrm{CI}$

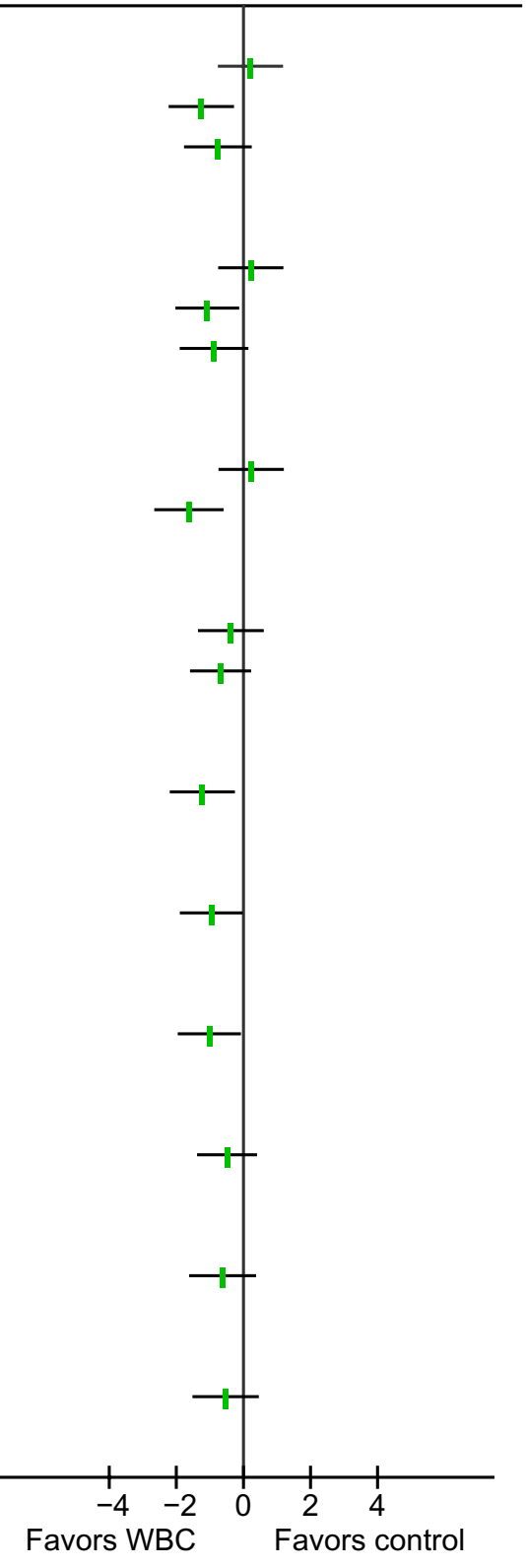

Figure I Forest plot of perceived sensation.

Abbreviations: IV, inverse variance; $\mathrm{Cl}$, confidence interval; WBC, whole-body cryotherapy.

\section{Clinical outcomes}

One study ${ }^{13}$ examined the effectiveness of WBC on recovery from a musculoskeletal injury. Participants with adhesive capsulitis were randomized to receive either physiotherapy alone or physiotherapy in addition to WBC. After 4 weeks of treatment, both groups improved in terms of pain, shoulder function, and range of movement (ROM). Between-group comparisons were significantly in favor of WBC for all outcomes; in most cases, these were clinically meaningful with large mean differences in ROM (MD $13^{\circ}$ abduction, $95 \%$ CI $9.2^{\circ}-16.8^{\circ}$; MD $5^{\circ}$ external rotation, $95 \% \mathrm{CI} 3.2^{\circ}-6.7^{\circ}$ ), pain (MD, $1.2 \mathrm{~cm}, 95 \% \mathrm{CI} 0.8-1.6$, based on a $10 \mathrm{~cm}$ visual analog scale), and shoulder function (MD 4 points, $95 \%$ CI 3.1-4.9, based on a 30-point scale). Of note, this study ${ }^{13}$ did not continue outcome assessment beyond the 4 weeks of treatment; therefore, any long-term effectiveness is unclear.

\section{Discussion}

This review examined the biochemical, physiological, and clinical effects of WBC. We found that most of the research in 
Study or subgroup

1.2.1 jump height 24 hours

Fonda $^{11}$

1.2.2 jump height $\mathbf{4 8}$ hours

Fonda $^{11}$

1.2.3 jump height 72 hours

Fonda ${ }^{11}$

1.2.4 jump height 96 hours

Fonda ${ }^{11}$

\subsection{5 strength 24 hours}

Fonda ${ }^{11}$

Hausswirth ${ }^{6}$

\subsection{6 strength 48 hours}

Fonda ${ }^{11}$

Hausswirth ${ }^{6}$

1.2.7 strength 72 hours

Fonda ${ }^{11}$

1.2.8 strength 96 hours

Fonda ${ }^{11}$

1.2.9 tennis performance (shot accuracy)

Ziemann $^{8}$

\section{Standard mean difference}

IV, fixed, $95 \% \mathrm{CI}$

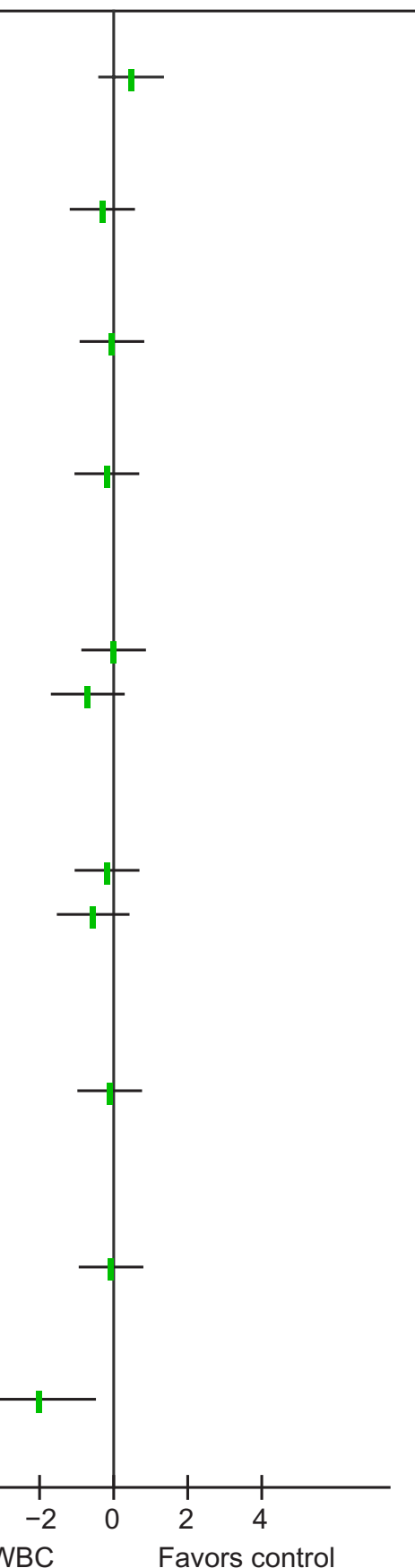

Figure 2 Forest plot of performance outcomes.

Abbreviations: IV, inverse variance $\mathrm{Cl}$, confidence interval; WBC, whole-body cryotherapy.

this area has been undertaken using small groups of younger (predominantly male) participants. In over half of the studies, the primary objective was to determine mechanisms of effect associated with WBC based on biochemical markers. A small number of studies focused on perceived recovery and performance-based measurement after various sport and exercise exposures. Only one study investigated the clinical effectiveness of WBC based on participants with significant musculoskeletal injury.

\section{Tissue-temperature reduction}

The premise of cryotherapy is to extract heat from the body tissue to attain various clinical effects. To optimize these effects, the best evidence suggests that a critical level of tissue 
cooling must be achieved..$^{30,31}$ As such, a key objective of this review was to determine the magnitude of tissue-temperature reductions associated with $\mathrm{WBC}$ and to compare with traditional forms of cooling (ice pack, CWI) used in sport and exercise medicine.

There is a supposition that because of its extreme temperatures $\left(-110^{\circ} \mathrm{C}\right)$, WBC offers an enhanced cooling effect over traditional forms of cryotherapy. It is clear that exposure to $-110^{\circ} \mathrm{C}$ creates a large thermal gradient between the skin and the environment $\left(\sim 140^{\circ} \mathrm{C}\right)$. However, heat transfer depends on a number of additional factors. For example, thermal conductivity or heat-transfer coefficient $\left(\mathrm{k}=\mathrm{W} / \mathrm{m}^{2}-\mathrm{K}\right)$ is the ability of a material to transfer heat. Ice has a much higher heat-transfer coefficient $(2.18 \mathrm{k})$ compared to both water $(0.58 \mathrm{k})$ and air $(0.024 \mathrm{k})$, meaning that it is a more efficient material for extracting heat energy from the body. Ice application also exploits phase change (change from solid into liquid), further enhancing its cooling potential. Although water and air are not the best media to transfer heat, a potential advantage is that they facilitate large surface areas of the body to be cooled simultaneously.

Comparisons across empirical studies suggest that the largest skin-temperature reductions are usually associated with crushed-ice application. Temperature reductions associated with CWI and WBC seem less intense, and in some reports these did not reach the critical temperatures necessary to optimize analgesia. ${ }^{30}$ Of note, intramuscular temperature reductions seem to be negligible, regardless of the mode of cooling. To date, only one study ${ }^{25}$ has examined the effect of WBC on intramuscular temperature, and future research addressing this gap in the literature is warranted.

The thermal properties of biological tissue mean that it is fundamentally difficult to cool below the skin surface. Subcutaneous adipose tissue has a very low thermal conductivity $(0.23 \mathrm{k}$; by comparison, muscle has a value of $0.46 \mathrm{k}),{ }^{32}$ causing it to have an insulating effect on the body. To our knowledge, the largest intramuscular temperature reduction $\left(1 \mathrm{~cm}\right.$ depth) reported in the clinical literature is $7^{\circ} \mathrm{C}^{33}$; interestingly, this was observed with an 8-minute ice-pack application in a sample of healthy participants with very low levels of adipose tissue (0-10 mm skin folds at the site of application). We have also recently demonstrated ${ }^{34}$ that the magnitude of temperature reduction also varies by body part, with bony regions such as the patella generally experiencing the largest reductions in tissue temperature.

\section{Adverse events}

We found no evidence of adverse effects within the current review. However, in accordance with previous reviews in this area, ${ }^{4,35}$ the majority of included studies did not seem to undertake active surveillance of predefined adverse events. Westerlund ${ }^{36}$ noted that no adverse effects had occurred during 8 years of WBC use within a specialist hospital in Finland. In recent years, a small number of isolated problems associated with WBC (eg, skin burns on the foot) have been publicized within the media; these events have been attributed to oversights during preparation, such as entering the chamber with wet skin or clothing. The skin surface has been reported to freeze from $-3.7^{\circ} \mathrm{C}$ to $-4.8^{\circ} \mathrm{C},{ }^{37}$ with serious cellular damage and cryotherapy skin burns occurring at a threshold of around $-10^{\circ} \mathrm{C} .{ }^{38}$ As few studies have reported skin-temperature reductions beyond $15^{\circ} \mathrm{C}$ with WBC, excessive tissue-temperature reductions seem unlikely, provided adequate procedures for patient preparation are followed, and relevant contraindications are adhered to: uncontrolled hypertension, serious coronary disease, arrhythmia, circulatory disorders, Raynaud's phenomenon (white fingers), cold allergies, serious pulmonary disease, or the obstruction of the bronchus caused by the cold. ${ }^{36}$

\section{Biomarkers}

There is evidence from animal models to suggest that cryotherapy can have a consistent effect on some important cellular and physiological events associated with inflammation after injury. These include cell metabolism, white blood cell activity within the vasculature, and potentially apoptosis. ${ }^{39-44} \mathrm{Few}$ studies have replicated these effects within human models. We highlighted two studies reporting an enhanced cytokine profile in athletes who used WBC after single ${ }^{7}$ or multiple training exposures. ${ }^{8}$ This should be regarded as preliminary evidence based on methodological limitations, including pseudorandomization and a risk of multiplicity. Others ${ }^{6,8,11}$ found little effect of WBC on various markers of muscle damage after various forms of exercise training. Evidence from recent reviews suggests that $\mathrm{CWI}^{3}$ and contrast water immersion ${ }^{35}$ have little to no effect on markers of inflammation or muscle damage after exercise. To our knowledge, only one study has quantified the biochemical effects of local ice-pack application within human subjects with significant injury. Using the microdialysis technique, Stålman et $\mathrm{al}^{45}$ reported that local icing and compression post-knee surgery resulted in a significantly lower production of prostaglandin $\mathrm{E}_{2}$ and synovial lactate compared to an untreated control group. 


\section{Oxidative stress}

There is evidence that CWI can induce oxidative stress and a possible increase in free radical species formation. ${ }^{46}$ Free radicals are produced both as a by-product of cellular metabolism in aerobic systems and from various environmental sources. When free radical production exceeds antioxidant protection capacity and repair mechanisms, oxidative stress occurs, resulting in damage to such macromolecules as proteins, lipids, and deoxyribonucleic acid. The relative risk of oxidative stress appears to increase during periods of metabolic stress, where there is a disruption to the prooxidant/antioxidant equilibrium. A related concept is that brief repeated exposure to cold temperatures can benefit athletes by activating adaptive homeostatic mechanisms in accordance with the hormetic dose-response model. ${ }^{5}$ Indeed, others have reported improvements in antioxidant capacity associated with regular exposure to cold-water swimming. ${ }^{46}$

Evidence from controlled studies on the effect of WBC on antioxidant capacity is equivocal. One study ${ }^{5}$ reported a lower production of oxidative stress when intense exercise was undertaken in conjunction with WBC, compared to exercise alone. Surprisingly, these findings did not fully align with the athlete's antioxidant profiles, as the WBC group had a lower concentration of superoxide dismutase and glutathione peroxidase over the 10-day training period. Although Miller et $\mathrm{al}^{9}$ found clearer evidence that WBC increases antioxidant activity in the absence of exercise, a limitation was that oxidative stress and antioxidant function were not quantified at the same site, and as such this makes it difficult to determine the mechanisms associated with oxidative stress. Furthermore, both these studies ${ }^{5,9}$ quantified oxidative stress using the thiobarbituric acid reactive substances (TBARS) assay, which has a number of limitations. ${ }^{47}$ For example, the TBARS assay claims to quantify the amount of malondialdehyde formed during the lipid-peroxidation process; a primary problem is that other substances such as biliverdin, glucose ribose, and 2-amino-pyrimidines all have the ability to be absorbed at or close to the same spectroscopic wavelength as TBARS $(532 \mathrm{~nm})$, and as such the assay generally reports inaccurate malondialdehyde concentrations when compared with more sophisticated techniques. Future studies should focus on the specific cell-signaling events leading to the increase in antioxidant protein expression and incorporate at least two or more indices of oxidative stress to confirm cell damage. In addition, direct measures of free radical production, such as electron paramagnetic resonance spectroscopy, would allow for a more accurate quantification of free radical generation and oxidative damage.

\section{Autonomic nervous system}

Finding efficient ways to influence the autonomic nervous system is a growing field in sports recovery. Intense exercise typically results in an increase in sympathetic activity, resulting in increased heart rate and decreased heart-rate variability. However, prolonged sympathetic activity is thought to be detrimental for postexercise recovery. As such, parasympathetic reactivation is currently considered to be an important indicator of systemic recovery, and often quantified using various indices of heart-rate variability. ${ }^{48}$

A small number of controlled studies have investigated the potential for using WBC to facilitate parasympathetic reactivation after exercise. Although there is evidence that WBC has an initial sympathetic effect, ${ }^{12}$ its summative effect seems to be parasympathetic. Indeed, Schaal et al ${ }^{14}$ reported that WBC enhances short-term autonomic recovery after intense exercise based on a two- to threefold increase in heart-rate variability. This response is thought to be mediated by the baroreflex, which is triggered by cold-induced vasoconstriction and an increase in central blood volume. ${ }^{49}$ As such, parasympathetic reactivation is not exclusive to WBC, and others ${ }^{50-52}$ have replicated these autonomic effects through CWI.

\section{Clinical outcomes}

We found conflicting evidence for the effect of WBC on correlates of functional recovery following sport. There was however clearer evidence that WBC could improve subjective outcomes, such as perceived recovery and muscle soreness. This aligns with findings from a recent Cochrane review $^{4}$ concluding that CWI has little effect on recovery postinjury beyond reductions in muscle soreness. Similarly, although there is consistent evidence to show that cold packs and/or crushed ice provides effective short-term analgesia after acute soft-tissue injury and postsurgery, ${ }^{53-55}$ there is little evidence to show any effect on functional restoration or swelling.

For the current review, we found one study ${ }^{13}$ concluding that WBC has a clinically important effect on recovery from musculoskeletal injury (adhesive capsulitis). The underpinning mechanisms for these effects are difficult to determine. Perhaps an important consideration is that this study ${ }^{13}$ used WBC in conjunction with standardized physiotherapy intervention involving manual therapy and joint mobilization. 
It is possible that WBC produced a local analgesia, or acted as a counterirritant to pain, which facilitated mobilization. Optimal analgesia is associated with skin temperatures of less than $13^{\circ} \mathrm{C},{ }^{30}$ a threshold that has been attained using standard WBC exposures in some reports. ${ }^{12,36}$ We also know that WBC increases norepinephrine, ${ }^{2}$ which could have an additional analgesic effect. ${ }^{56}$ Local cooling can have an additional excitatory effect on muscle activation; this has been observed in both healthy and injured adults, ${ }^{57-60}$ providing further evidence that cooling can be an important adjunct to therapeutic exercise.

\section{Benefits, harms, and recommendations for future research}

When assessing therapeutic interventions, it is important to compare any benefits with possible risks and harms. In accordance with previous reviews, ${ }^{2}$ we found that WBC can modify many important biochemical and physiological parameters in human athletes. We also found trends that WBC can improve subjective recovery and muscle soreness following metabolic or mechanical overload. This evidence should still be regarded as preliminary, and further highquality randomized studies are recommended.

It is difficult to reach a definitive conclusion on possible risks associated with WBC, as studies have not undertaken active surveillance of predefined adverse events. This should be addressed within future studies; the constant pressure to maximize sporting performance means that athletes often experiment with extreme exposures and interventions. Current recommendations for WBC parameters, including optimal air temperatures and the duration and frequency of exposure, are largely based on anecdote. It is imperative that safe guidelines are developed using evidence-based information. Future studies should also determine whether it is necessary to alter the dose of therapy based on the nature of the injury, the severity, or the level of chronicity.

WBC is often regarded as a superior mode of cooling, due to its extreme temperatures. However, there is no strong evidence that it offers any distinct advantages over traditional methods of cryotherapy. There is much evidence to show that CWI and ice-pack application are both capable of inducing clinically relevant reductions in tissue temperature, and that they also provide important physiological and clinical effects. ${ }^{3,4,30,46,50,55}$ Future research should directly compare the relative effectiveness of $\mathrm{WBC}, \mathrm{CWI}$, and ice-pack application. An important limitation is that WBC is currently significantly more expensive and much less accessible than either CWI or ice packs.

\section{Conclusion}

WBC induces tissue-temperature reductions that are comparable to or less significant than traditional forms of cryotherapy. Controlled studies suggest that WBC could have a positive influence on inflammatory mediators, antioxidant capacity, and autonomic function during sporting recovery; however, these findings are preliminary. Although there is some evidence that WBC improves the perception of recovery and soreness after various sports and exercise, this does not seem to translate into enhanced functional recovery. Only one study has focused on recovery after significant musculoskeletal injury, and long-term implications are unclear. Until further research is available, athletes should remain cognizant that less expensive modes of cryotherapy, such as local ice-pack application or CWI, offer comparable physiological and clinical effects to WBC.

\section{Disclosure}

The authors report no conflicts of interest in this work

\section{References}

1. Hirvonen HE, Mikkelsson MK, Kautiainen H, Pohjolainen TH, Leirisalo-Repo M. Effectiveness of different cryotherapies on pain and disease activity in active rheumatoid arthritis. A randomised single blinded controlled trial. Clin Exp Rheumatol. 2006;24:295-301.

2. Banfi G, Lombardi G, Colombini A, Melegati G. Whole-body cryotherapy in athletes. Sports Med. 2010;40:509-517.

3. Bleakley CM, Glasgow PD, Philips P, et al. Guidelines on the Management of Acute Soft Tissue Injury Using Protection Rest Ice Compression and Elevation. London: ACPSM; 2011.

4. Bleakley C, McDonough S, Gardner E, Baxter GD, Hopkins JT, Davison GW. Cold-water immersion (cryotherapy) for preventing and treating muscle soreness after exercise. Cochrane Database Syst Rev. 2012;2:CD008262.

5. Mila-Kierzenkowska C, Woźniak A, Woźniak B, et al. Whole body cryostimulation in kayaker women: a study of the effect of cryogenic temperatures on oxidative stress after the exercise. $J$ Sports Med Phys Fitness. 2009;49:201-207.

6. Hausswirth C, Louis J, Bieuzen F, et al. Effects of whole-body cryotherapy vs far-infrared vs passive modalities on recovery from exercise-induced muscle damage in highly-trained runners. PloS One. 2011;6:e27749.

7. Pournot H, Bieuzen F, Louis J, Fillard JR, Barbiche E, Hausswirth C. Time course of changes in inflammatory response after whole-body cryotherapy multi exposures following severe exercise. PloS One. 2011;6:e22748.

8. Ziemann E, Olek RA, Kujach S, et al. Five-day whole-body cryostimulation, blood inflammatory markers, and performance in high-ranking professional tennis players. JAthl Train. 2012;47:664-672.

9. Miller E, Markiewicz L, Saluk J, Majsterek I. Effect of short-term cryostimulation on antioxidative status and its clinical applications in humans. Eur J Appl Physiol. 2012;112:1645-1652.

10. Costello JT, Algar LA, Donnelly AE. Effects of whole body cryotherapy $\left(-110^{\circ} \mathrm{C}\right)$ on proprioception and indices of muscle damage. Scand $J$ Med Sci Sports. 2012;22:190-198.

11. Fonda B, Sarabon N. Effects of whole-body cryotherapy on recovery after hamstring damaging exercise: a crossover study. Scand J Med Sci Sports. 2013;23:e270-e278.

12. Hausswirth C, Schaal K, Le Meur Y, et al. Parasympathetic activity and blood catecholamine responses following a single partial-body cryostimulation and a whole-body cryostimulation. PLoS One. 2013;22:e72658. 
13. Ma SY, Je HD, Jeong JH, Kim HY, Kim HD. Effects of whole-body cryotherapy in the management of adhesive capsulitis of the shoulder. Arch Phys Med Rehabil. 2013;94:9-16.

14. Schaal K, Le Meur Y, Bieuzen F, et al. Effect of recovery mode on postexercise vagal reactivation in elite synchronized swimmers. Appl Physiol Nutr Metab. 2013;38:126-133.

15. Tomchuk D, Rubley MD, Holcomb WR, Guadagnoli M, Tarno JM. The magnitude of tissue cooling during cryotherapy with varied types of compression. J Athl Train. 2010;45:230-237.

16. Jutte LS, Merrick MA, Ingersoll CD, Edwards JE. The relationship between intramuscular temperature, skin temperature, and adipose thickness during cryotherapy and rewarming. Arch Phys Med Rehabil. 2001;82:845-850.

17. Chesterton LS, Foster NE, Ross L. Skin temperature response to cryotherapy. Arch Phys Med Rehabil. 2002;83:543-549.

18. Kanlayanaphotporn R, Janwantanakul P. Comparison of skin surface temperature during the application of various cryotherapy modalities. Arch Phys Med Rehabil. 2005;86:1411-1415.

19. Merrick MA, Jutte LS, Smith ME. Cold modalities with different thermodynamic properties produce different surface and intramuscular temperatures. J Athl Train. 2003;38:28-33.

20. Palmer JE, Knight KL. Ankle and thigh skin surface temperature changes with repeated ice pack application. J Athl Train. 1996;31:319-323.

21. Zemke JE, Andersen JC, Guion WK, McMillan J, Joyner AB. Intramuscular temperature responses in the human leg to two forms of cryotherapy: ice massage and ice bag. J Orthop Sports Phys Ther. 1998;27:301-307.

22. Myrer JW, Measom G, Durrant E, Fellingham GW. Cold and hot pack contrast therapy: subcutaneous and intramuscular temperature change. J Athl Train. 1997;32:238-241.

23. Palmieri RM, Garrison JC, Leonard JL, Edwards JE, Weltman A, Ingersoll CD. Peripheral ankle cooling and core body temperature. J Athl Train. 2006;41:185-188.

24. Gregson W, Black MA, Jones H, et al. Influence of cold water immersion on limb and cutaneous blood flow at rest. Am J Sports Med. 2011;39: 1316-1323.

25. Costello JT, Culligan K, Selfe J, Donnelly AE. Muscle, skin and core temperature after $-110^{\circ} \mathrm{C}$ cold air and $8^{\circ} \mathrm{C}$ water treatment. PLoS One. 2012;7:e48190.

26. Costello JT, Donnelly AE, Karki A, Selfe J. Effects of whole body cryotherapy and cold water immersion on knee skin temperature. Int $J$ Sports Med. Epub June 18, 2013.

27. Cholewka A, Stanek A, Sieroń A, Drzazga Z. Thermography study of skin response due to whole-body cryotherapy. Skin Res Technol. 2012;18:180-187.

28. Cholewka A, Drzazga Z, Sieron A, Stanek A. Thermovision diagnostics in chosen spine diseases treated by whole body cryotherapy. $J$ Therm Anal Calorim. 2010;102:113-119.

29. Westerlund T, Oksa J, Smolander J, Mikkelsson M. Thermal responses during and after whole-body cryotherapy. J Therm Biol. 2003;28: 601-608.

30. Bleakley CM, Hopkins JT. Is it possible to achieve optimal levels of tissue cooling in cryotherapy? Phys Ther Rev. 2010;15:344-350.

31. Bleakley CM, Glasgow P, Webb MJ. Cooling an acute muscle injury: can basic scientific theory translate into the clinical setting? Br J Sports Med. 2012;46:296-298.

32. El-Brawany MA, Nassiri DK, Terhaar G, Shaw A, Rivens I, Lozhken K. Measurement of thermal and ultrasonic properties of some biological tissues. J Med Eng Technol. 2009;33:249-256.

33. Otte JW, Merrick MA, Ingersoll CD, Cordova ML. Subcutaneous adipose tissue thickness alters cooling time during cryotherapy. Arch Phys Med Rehabil. 2002;83:1501-1505.

34. Costello J, McInerney CD, Bleakley CM, Selfe J, Donnelly A. The use of thermal imaging in assessing skin temperature following cryotherapy: a review. J Therm Biol. 2012;37:103-110.

35. Bieuzen F, Bleakley CM, Costello JT. Contrast water therapy and exercise induced muscle damage: a systematic review and meta-analysis. PLoS One. 2013;8:e62356.
36. Westerlund T. Thermal, Circulatory, and Neuromuscular Responses to Whole-Body Cryotherapy [doctoral thesis]. Oulu, Finland: University of Oulu; 2009.

37. Danielsson U. Windchill and the risk of tissue freezing. J Appl Physiol (1985). 1996;81:2666-2673.

38. Gage AA. What temperature is lethal for cells? J Dermatol Surg Oncol. 1979;5:459-460.

39. Farry PJ, Prentice NG, Hunter AC, Wakelin CA. Ice treatment of injured ligaments: an experimental model. N Z Med J. 1980;91:12-14.

40. Hurme T, Rantanen J, Kalimo H. Effects of early cryotherapy in experimental skeletal muscle injury. Scand J Med Sci Sports. 1993;3:46-51.

41. Westermann S, Vollmar B, Thorlacius H, Menger MD. Surface cooling inhibits tumor necrosis factor-alpha-induced microvascular perfusion failure, leukocyte adhesion, and apoptosis in the striated muscle. Surgery. 1999;126:881-889.

42. Lee H, Natsui H, Akimoto T, Yanagi K, Ohshima N, Kono I. Effects of cryotherapy after contusion using real-time intravital microscopy. Med Sci Sports Exerc. 2005;37:1093-1098.

43. Schaser KD, Stover JF, Melcher I, et al. Local cooling restores microcirculatory hemodynamics after closed soft-tissue trauma in rats. J Trauma. 2006;61:642-649.

44. Schaser KD, Disch AC, Stover JF, Lauffer A, Bail HJ, Mittlmeier T. Prolonged superficial local cryotherapy attenuates microcirculatory impairment, regional inflammation, and muscle necrosis after closed soft tissue injury in rats. Am J Sports Med. 2007;35:93-102.

45. Stålman A, Tsai JA, Wredmark T, Dungner E, Arner P, Felländer-Tsai L. Local inflammatory and metabolic response in the knee synovium after arthroscopy or arthroscopic anterior cruciate ligament reconstruction. Arthroscopy. 2008;24:579-584.

46. Bleakley CM, Davison GW. What is the biochemical and physiological rationale for using cold-water immersion in sports recovery? A systematic review. Br J Sports Med. 2010;44:179-187.

47. Powers SK, Smuder AJ, Kavazis AN, Hudson MB. Experimental guidelines for studies designed to investigate the impact of antioxidant supplementation on exercise performance. Int J Sport Nutr Exerc Metab. 2010;20:2-14

48. Seiler S, Haugen O, Kuffel E. Autonomic recovery after exercise in trained athletes: intensity and duration effects. Med Sci Sports Exerc. 2007;39:1366-1373.

49. Pump B, Shiraishi M, Gabrielsen A, Bie P, Christensen NJ, Norsk P. Cardiovascular effects of static carotid baroreceptor stimulation during water immersion in humans. Am J Physiol Heart Circul Physiol. 2001;280:H2607-H2615.

50. Buchheit M, Peiffer JJ, Abbiss CR, Laursen PB. Effect of cold water immersion on postexercise parasympathetic reactivation. Am J Physiol Heart Circ Physiol. 2009;296:H421-H427.

51. Al Haddad H, Laursen PB, Ahmaidi S, Buchheit M. Influence of cold water face immersion on post-exercise parasympathetic reactivation. Eur J Appl Physiol. 2010;108:599-606.

52. Stanley J, Buchheit M, Peake JM. The effect of post-exercise hydrotherapy on subsequent exercise performance and heart rate variability. Eur J Appl Physiol. 2011;2:951-961.

53. Airaksinen OV, Kyrklund N, Latvala K, Kouri JP, Grönblad M, Kolari P. Efficacy of cold gel for soft tissue injuries: a prospective randomized double-blinded trial. Am J Sports Med. 2003;31:680-684.

54. Bleakley CM, McDonough SM, MacAuley DC. Cryotherapy for acute ankle sprains: a randomised controlled study of two different icing protocols. Br J Sports Med. 2006;40:700-705.

55. Bleakley C, McDonough S, MacAuley D. The use of ice in the treatment of acute soft-tissue injury: a systematic review of randomised controlled trials. Am J Sports Med. 2004;32:251-261.

56. Pertovaara A, Kalmari J. Comparison of the visceral antinociceptive effects of spinally administered MPV-2426 (fadolmidine) and clonidine in the rat. Anesthesiology. 2003;92:189-194.

57. Rice D, McNair PJ, Dalbeth N. Effects of cryotherapy on arthrogenic muscle inhibition using an experimental model of knee swelling. Arthritis Rheum. 2009;61:78-83. 
58. Hopkins JT, Hunter I, McLoda T. Effects of ankle joint cooling on peroneal short latency response. J Sports Sci Med. 2006;5:333-339.

59. Hopkins J, Ingersoll CD, Edwards J, Klootwyk TE. Cryotherapy and transcutaneous electric neuromuscular stimulation decrease arthrogenic muscle inhibition of the vastus medialis after knee joint effusion. JAthl Train. 2002;37:25-31.
60. Hopkins JT. Knee joint effusion and cryotherapy alter lower chain kinetics and muscle activity. J Athl Train. 2006;41:177-184.

\section{Publish your work in this journal}

Open Access Journal of Sports Medicine is an international, peer-reviewed, open access journal publishing original research, reports, reviews and commentaries on all areas of sports medicine. The manuscript management system is completely online and includes a very quick and fair peer-review system.
Visit http://www.dovepress.com/testimonials.php to read real quotes from published authors. 